\title{
Biomat Development in Soil Treatment Units for On-site Wastewater Treatment
}

\author{
H.F. Winstanley • A.C. Fowler
}

Received: 28 January 2013 / Accepted: 16 July 2013 / Published online: 10 August 2013

(C) Society for Mathematical Biology 2013

\begin{abstract}
We provide a simple mathematical model of the bioremediation of contaminated wastewater leaching into the subsoil below a septic tank percolation system. The model comprises a description of the percolation system's flows, together with equations describing the growth of biomass and the uptake of an organic contaminant concentration. By first rendering the model dimensionless, it can be partially solved, to provide simple insights into the processes which control the efficacy of the system. In particular, we provide quantitative insight into the effect of a near surface biomat on subsoil permeability; this can lead to trench ponding, and thus propagation of effluent further down the trench. Using the computed vadose zone flow field, the model can be simply extended to include reactive transport of other contaminants of interest.
\end{abstract}

Keywords On-site wastewater · Pore clogging

\section{Introduction}

A typical on-site domestic wastewater treatment system consists of a septic tank whose outflow is distributed over a percolation area by a number of perforated pipes. The tank allows for sedimentation of solids and some anaerobic digestion, notably the mineralization of organic nitrogen to ammonium. It also provides a degree of buffering of the flow rate of effluent into the percolation area, where wastewater from the perforated pipes percolates into the underlying, unsaturated native soil. The purpose of on-site wastewater treatment systems is to allow safe natural attenuation of

H.F. Winstanley $(\bowtie) \cdot$ A.C. Fowler

MACSI, University of Limerick, Limerick, Ireland

e-mail: henry.winstanley@ul.ie

A.C. Fowler

OCIAM, University of Oxford, Oxford, UK 
contaminants and pathogens from domestic wastewater by microbial populations in the soil vadose zone. The primary aim is that contaminant and pathogen concentrations reaching the water table are within acceptable levels. Since the treatment aims are mainly achieved in the soil column rather than the septic tank, the percolation trenches and soil column are together commonly referred to as a soil treatment unit (STU).

Within the percolation trench, the space between the perforated distribution pipe and the infiltrative surface (IS) of the native soil is most commonly filled with coarse gravel in existing installations, though recent open chamber systems can offer some advantages (Lowe and Siegrist 2008). Flow of septic tank effluent (STE) through the system promotes bacterial growth in the soil column, and over a timescale of months leads to the formation of a bacterial biomat (alternatively, clogging zone or biozone) at and immediately below the IS. The biomat can be several orders of magnitude less permeable than the native soil due to pore clogging by organic matter, comprising biomass and biomass-derived material (cellular detritus and a highly waterretaining matrix of exopolysaccharides (EPS)) together with any effluent-derived suspended solids entrapped by physical filtration. McKinley and Siegrist (2010, 2011), for instance, distinguish what they term a biomat of $O(1 \mathrm{~cm})$ depth due to a combination of biomass growth and accumulation of suspended solids by filtration, and an additional biozone of extensive biological activity extending $O(10 \mathrm{~cm})$ below the IS.

The relatively low permeability of the biomat has the dual effect of (i) slowing the downward percolation of wastewater into the soil, thereby increasing the residence time and attenuation in the soil column, and (ii) distributing the wastewater flow over a greater length of the percolation trench, thereby increasing the total soil grain surface area and microbiota contributing to the treatment.

The biomat takes some months to become fully established following construction, and its extent and quality appear to determine the long-term achievement of the treatment goals. In particular, Gill et al. (2007, 2009) observed that secondary treated effluent inputs to the percolation field can paradoxically lead to regions of higher contaminant concentration at depth in the soil than septic tank effluent inputs of higher contaminant content. They argued that the lower organic concentrations of the secondary treated inputs lead to a thinner, more permeable biomat, resulting in localization of wastewater flow in a shorter region at the upstream end of the percolation trench.

Treatment outcomes also depend on the properties of the native soil beneath the percolation trenches. Gill et al. (2009) suggested that reduced attenuation in freely draining soils may be due to a muted spread of biomat and a resulting concentration of hydraulic loading in the upstream region of the trench. Biomat in moderately percolating soils results in distribution of the flow over a greater area.

This paper sets out a simple modeling framework for describing the effect of the biomat on the distribution of wastewater flow in and below a single percolation trench. We focus on modeling the extent and quality of biomat formation under different effluent and soil conditions. The area over which the effluent is distributed is a major determinant of overall contaminant attenuation and the achievement of treatment objectives. 


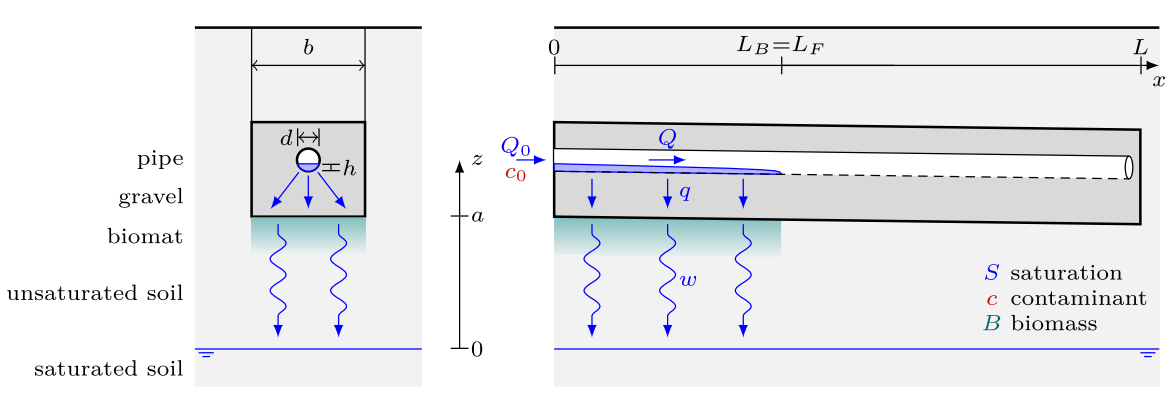

Fig. 1 Schematic transverse and longitudinal trench cross sections in the absence of ponding at the trench base

Modeling studies in the literature have largely assumed biomat hydraulic properties are given, and used numerical simulation packages such as HYDRUS2D (Šimůnek et al. 2011) and its reactive transport modules (CW2D (Langergraber and Šimůnek 2005) and CWM1 (Langergraber et al. 2009)) to investigate varying hydraulic régimes and compare open and gravel IS architectures in a 2D plane perpendicular to the trench (Huntzinger Beach and McCray 2003; Radcliffe et al. 2005; Finch et al. 2008; Beal et al. 2008; Wunsch et al. 2009). Our approach differs in proposing a minimal analytical model to describe the biomat development along the IS by coupling the flow and transport with biomass growth, which we then investigate through analytical approximations. In keeping with this approach, and in the interests of simple exposition and analysis, we omit here much of the detail that is commonly included in numerical simulation models, such as multicomponent contaminant reaction and speciation specifics. The present model is straightforwardly extended to include reactive transport of other contaminants of interest.

In addition to providing some mechanistic understanding, such a model has potential for informing the scientific grounding of Codes of Practice for new installations (Gill 2011). For example, a question of interest is determining the optimal length and number of percolation trenches for a given site. A possible application of particular relevance in Ireland is in supporting the design of effective inspection protocols for existing installations, since the EU Water Framework Directive and the 2009 ruling of the European Court of Justice against Ireland require an urgent comprehensive inspection régime to be implemented for the circa 500,000 domestic septic tank systems currently installed.

\section{Soil Treatment Unit Model}

We assume that a water layer of thickness $h$ in the perforated outflow pipe drains through a gravel layer to unsaturated subsoil of depth $a$ above the water table, as illustrated in Fig. 1. The soil contains microbiological colonies, whose density is liable to increase near the gravel, forming a biomat. In a simple model, we would consider the biomat as a separate layer with its own permeability, but here we suppose that bacteria thrive throughout the subsoil. We also ignore clogging by physical filtration of suspended solids in the pore network, though the accumulation and aging of 
organic solids (whether originating from filtration or biomat turnover) merit further study given their potential significance.

\subsection{Along-Pipe Flow}

One of the issues arising from consideration of secondary treatment systems is that biomat growth may be limited in the horizontal, along-pipe direction. More generally, we may be interested in the correct length of pipe to install for a given wastewater flow. The along-pipe flow $\left[L^{3} T^{-1}\right]$ is taken to be ${ }^{1}$

$$
Q=\frac{K_{p} \rho g d h^{3}}{\eta_{w}}\left(s_{0}-h_{x}\right),
$$

where $s_{0}$ is the pipe slope, $d$ is the pipe width, $x$ is distance along the pipe, $\rho$ is the effluent density, $g$ is the acceleration due to gravity, $h$ is the fluid depth, $\eta_{w}$ is the dynamic viscosity, and $K_{p}$ is a shape factor; for a flat-bottomed pipe $K_{p}=\frac{1}{3}$, and less for a round pipe. We use subscripts $x, t$, and $z$ to denote partial derivatives with respect to these independent variables. The wastewater flow varies along the pipe due to the loss to the gravel-filled trench, so that conservation of wastewater mass takes the form

$$
T h_{t}+Q_{x}=-q,
$$

where $0<T(h) \leq d$ is the flow surface width, and we may take the leakage flow rate $q\left[L^{2} T^{-1}\right]$ per unit pipe length to be

$$
q=T_{p} h
$$

where $T_{p}\left[L T^{-1}\right]$ is the transmissivity of the pipe, with a value dependent on the size and spacing of perforations in the pipe. The boundary conditions for (2) are those of a prescribed inflow and zero outflow:

$$
\begin{array}{ll}
Q=Q_{0} & \text { at } x=0, \\
Q=0 & \text { at } x=L .
\end{array}
$$

\subsection{Soil Drainage}

Unsaturated flow is modeled by the Richards' equation with biomass-dependent effective porosity and permeability. We suppose that the soil has porosity $\phi$, and that $\rho_{B}$ is the biomass per unit volume of pore space (measured in $\operatorname{mg}_{\mathrm{COD}} 1^{-1}$ including cells and slime matrix) that would completely fill the pore space. Thus, if $B$ is the actual density of biomass in the pore space, then $\phi\left(1-\frac{B}{\rho_{B}}\right)$ is the effective pore volume fraction. If $S$ is the water saturation of the effective pore space, then $\phi\left(1-\frac{B}{\rho_{B}}\right) S$

\footnotetext{
${ }^{1}$ Based on steady laminar open flow in a wide, flat-bottomed channel. Given the likely sectional variation due to sludge build-up, we ignore depth-dependence of $K_{p}$ in other pipe sections in favor of a simple model.
} 
is the effective moisture content. Equations describing the vertical percolation in the subsoil are given by

$$
\begin{aligned}
{\left[\phi\left(1-\frac{B}{\rho_{B}}\right) S\right]_{t}-w_{z} } & =0, \\
w & =\frac{k_{0}(B) k_{r}(S)}{\eta_{w}}\left(p_{z}+\rho g\right), \\
p_{a}-p & =f(S),
\end{aligned}
$$

where $w$ is the downward water flux, $k_{0}$ is the saturated permeability, $k_{r}$ is the relative permeability, $p$ is pressure, $p_{a}$ is air pressure, and $f(S)$ is the capillary suction, with $f(1)=0 ; f$ is a monotonically decreasing function of $S$. The functions $f$ and $k_{r}$ will depend on the soil; here we adopt the choices

$$
f=f_{0}(1-S), \quad k_{r}=S^{3} \text {. }
$$

We take the vertical coordinate $z$ to have its origin at the water table. Suitable boundary conditions for the flow are then

$$
\begin{aligned}
& S=1 \quad \text { at } z=0, \\
& w=\frac{q}{b} \quad \text { at } z=a,
\end{aligned}
$$

where $q$ is the flux from the gravel layer and $b$ is the width of the trench base over which the effluent flow is distributed.

\subsection{Microbial Activity}

The soil contains a variety of microbial populations with different metabolic capabilities. These populations grow in response to the range and concentrations of contaminants in the effluent, which are degraded accordingly. The microbial biomat in the STU results from the pore clogging effect of the combination of these microbial populations, and is therefore dependent on multiple contaminants. For the purposes of the current model we give a simplified description based on a single contaminant and degradation pathway, and choose organic carbon loading, as measured by chemical oxygen demand (COD), on the basis that heterotrophic bacterial growth dominates the clogging effect in the biozone. The analysis is, however, easily extended to the multicomponent, multipathway situation.

We assume the biomass density $B$ satisfies the equation

$$
B_{t}=r-\mu_{d} B
$$

where $r$ represents a Monod growth term, most simply

$$
r=\frac{\mu_{B} B c}{K_{c}+c},
$$


dependent primarily on an assumed organic contaminant concentration $c$, and the second term in (8) represents mortality. Since the equation is linear in $B$, it misleadingly suggests unlimited growth in the contaminant-rich top layer next to the trench base. In reality, saturation will occur, most simply because $c$ is depleted by bacterial growth. More specifically, we might suppose the uptake rate is also proportional to the specific surface area per unit volume $\varsigma$, which will be a decreasing function of $B$, with $\varsigma \rightarrow 0$ as $\frac{B}{\rho_{B}} \rightarrow 1$. Thus, we take

$$
r=\frac{\mu_{B} B c}{K_{c}+c} \frac{\varsigma(B)}{\varsigma_{0}},
$$

where $\varsigma_{0}=\varsigma(0)$ is the specific surface area of the clean soil. This provides an explicit mechanism for saturation of $B$ in (8).

\subsection{Contaminant Attenuation}

In the subsoil, the contaminant concentration is given by an advection-dispersionreaction equation,

$$
\left[\phi\left(1-\frac{B}{\rho_{B}}\right) S c\right]_{t}-(w c)_{z}=-\frac{r}{Y}+D_{T} c_{z z},
$$

where $Y$ is a yield coefficient, and $D_{T}$ is a dispersion coefficient. Suitable boundary conditions, assuming an efficient basal aquifer, are

$$
\begin{array}{ll}
c=c_{0} & \text { at } z=a, \\
c=0 & \text { at } z=0 .
\end{array}
$$

Further contaminants of interest can easily be modelled on a similar basis, but we propose coupling the biomat growth and consequent permeability reduction to uptake of $c$ alone.

\section{Nondimensionalization}

We scale the model by taking

$$
\begin{aligned}
& x \sim L, \quad z \sim a, \quad t \sim \frac{a}{K_{0}}, \quad Q \sim Q_{0}, \quad h \sim h_{0} \equiv\left(\frac{Q_{0} \eta_{w}}{K_{p} s_{0} \rho g}\right)^{1 / 3}, \\
& c \sim c_{0}, \quad T \sim d, \quad q \sim K_{0} d, \quad w \sim K_{0}, \quad B \sim \rho_{B}, \quad r=\rho_{B} \mu_{B} R, \\
& p-p_{a} \sim \rho g a, \quad f=f_{0} \psi, \quad k_{0}(B)=k_{00} \kappa\left(\frac{B}{\rho_{B}}\right), \quad \varsigma(B)=\varsigma_{0} \Sigma\left(\frac{B}{\rho_{B}}\right),
\end{aligned}
$$

where $K_{0}$ is the saturated hydraulic conductivity,

$$
K_{0}=\frac{\rho g k_{00}}{\eta_{w}}, \quad k_{00}=\left.k_{0}\right|_{B=0} .
$$


The functions $\kappa(B)$ and $\Sigma(B)$ are decreasing, with

$$
\kappa(0)=\Sigma(0)=1, \quad \kappa(1)=\Sigma(1)=0,
$$

and for computational purposes we choose

$$
\kappa(B)=\Sigma(B)=1-B .
$$

The resulting dimensionless groundwater model takes the form

$$
\begin{aligned}
{[\phi(1-B) S]_{t}-w_{z} } & =0, \\
w & =\kappa(B)\left[k_{r}(S)+\Gamma D(S) S_{z}\right],
\end{aligned}
$$

where the diffusivity $D>0$ is

$$
D=-k_{r}(S) \psi^{\prime}(S)
$$

For the choices in (6),

$$
D=S^{3}
$$

The parameter $\Gamma$ is defined by

$$
\Gamma=\frac{f_{0}}{\rho g a} .
$$

The contaminant and biomass equations in the soil take the form

$$
\begin{aligned}
{[\phi(1-B) S c]_{t}-(w c)_{z} } & =-\frac{\gamma R}{\varepsilon}+\frac{1}{P e} c_{z z}, \\
B_{t} & =\gamma(R-\lambda B), \\
R & =\frac{B \Sigma(B) c}{\kappa_{c}+c}
\end{aligned}
$$

where the parameters are defined by

$$
\kappa_{c}=\frac{K_{c}}{c_{0}}, \quad \gamma=\frac{\mu_{B} a}{K_{0}}, \quad P e=\frac{K_{0} a}{D_{T}}, \quad \varepsilon=\frac{Y c_{0}}{\rho_{B}}, \quad \lambda=\frac{\mu_{d}}{\mu_{B}} .
$$

Water flow in the pipe is described by

$$
\begin{aligned}
\delta h_{t}+Q_{x} & =-\Omega q, \\
q & =\Theta h, \\
Q & =h^{3}\left[1-v h_{x}\right],
\end{aligned}
$$

where

$$
\delta=\frac{K_{0} L h_{0} d}{Q_{0} a}, \quad \Omega=\frac{K_{0} L d}{Q_{0}}, \quad v=\frac{h_{0}}{L s_{0}}, \quad \Theta=\frac{T_{p} h_{0}}{K_{0} d}
$$


Table 1 Assumed values of the constants in the model. Those marked ${ }^{\star}{ }^{\star}$ are calculated from the other constants

\begin{tabular}{|c|c|c|c|}
\hline Category & Symbol & Meaning & Typical value \\
\hline \multirow[t]{2}{*}{ Effluent } & $c_{0}$ & inlet contamination concentration & $1,000 \mathrm{mg}_{\mathrm{COD}} 1^{-1}$ \\
\hline & $Q_{0}$ & wastewater inlet flux & $0.15 \mathrm{~m}^{3} \mathrm{~d}^{-1}$ \\
\hline \multirow[t]{9}{*}{ Trench } & $a$ & vadose zone depth & $1 \mathrm{~m}$ \\
\hline & $s_{0}$ & pipe slope & 0.005 \\
\hline & $d$ & pipe width & $0.1 \mathrm{~m}$ \\
\hline & $b$ & trench width & $0.5 \mathrm{~m}$ \\
\hline & $h_{0}$ & pipe flow depth scale ${ }^{(\star)}$ & $1.5 \mathrm{~mm}$ \\
\hline & $K_{G}$ & gravel conductivity & $10^{4} \mathrm{~m} \mathrm{~d}^{-1}$ \\
\hline & $K_{p}$ & pipe shape factor & 0.1 \\
\hline & $L$ & pipe/trench length & $18 \mathrm{~m}$ \\
\hline & $T_{p}$ & pipe transmissivity & $70 \mathrm{~m} \mathrm{~d}^{-1}$ \\
\hline \multirow[t]{6}{*}{ Soil } & $d_{g}$ & soil grain size & $0.1 \mathrm{~mm}$ \\
\hline & $D_{T}$ & dispersion coefficient & $10^{-9} \mathrm{~m}^{2} \mathrm{~s}^{-1}$ \\
\hline & $f_{0}$ & suction pressure scale ${ }^{(\star)}$ & $6 \times 10^{4} \mathrm{~Pa}$ \\
\hline & $k_{00}$ & clean soil permeability ${ }^{(\star)}$ & $6 \times 10^{-13} \mathrm{~m}^{2}$ \\
\hline & $K_{0}$ & clean soil hydraulic conductivity & $0.5 \mathrm{~m} \mathrm{~d}^{-1}$ \\
\hline & $\phi$ & soil porosity & 0.4 \\
\hline \multirow[t]{5}{*}{ Biomass } & $K_{c}$ & Monod constant & $2 \mathrm{mg}_{\mathrm{COD}} 1^{-1}$ \\
\hline & $Y$ & yield coefficient & $0.63 \mathrm{mg}_{\mathrm{COD}} \mathrm{mg}_{\mathrm{COD}}^{-1}$ \\
\hline & $\mu_{B}$ & Monod growth rate & $3 d^{-1}$ \\
\hline & $\mu_{d}$ & mortality rate & $0.2 \mathrm{~d}^{-1}$ \\
\hline & $\rho_{B}$ & biomass density & $5000 \mathrm{mg}_{\mathrm{COD}} 1^{-1}$ \\
\hline \multirow[t]{4}{*}{ General } & $g$ & gravity & $9.8 \mathrm{~m} \mathrm{~s}^{-2}$ \\
\hline & $\eta_{w}$ & water viscosity & $10^{-3} \mathrm{Pas}$ \\
\hline & $\rho$ & water density & $10^{3} \mathrm{~kg} \mathrm{~m}^{-3}$ \\
\hline & $\sigma$ & surface tension & $73 \mathrm{mNm}^{-1}$ \\
\hline
\end{tabular}

Boundary conditions for the equations in the subsoil take the form

$$
\begin{aligned}
& S=1, \quad c=0 \quad \text { at } z=0, \\
& w=\Lambda q, \quad c=1 \quad \text { at } z=1,
\end{aligned}
$$

with

$$
\Lambda=\frac{d}{b},
$$

while those for the pipe flow are

$$
Q= \begin{cases}1 & \text { at } x=0, \\ 0 & \text { at } x=1\end{cases}
$$


Table 2 Typical values of the dimensionless parameters

\begin{tabular}{llll}
\hline Parameter & Typical value & Parameter & Typical value \\
\hline$P e=\frac{K_{0} a}{D_{T}}$ & $5.8 \times 10^{3}$ & $\Theta=\frac{T_{p} h_{0}}{K_{0} d}$ & 2.1 \\
$\alpha=\frac{K_{0} L}{K_{G} s_{0} a}$ & 0.18 & $\kappa_{c}=\frac{K_{c}}{c_{0}}$ & $2.0 \times 10^{-3}$ \\
$\beta=\frac{Q_{0}}{K_{G} L b s_{0}^{2}}$ & 0.067 & $\lambda=\frac{\mu_{d}}{\mu_{B}}$ & 0.067 \\
$\gamma=\frac{\mu_{B} a}{K_{0}}$ & 6.0 & $\Lambda=\frac{d}{b}$ & 0.20 \\
$\Gamma=\frac{f_{0}}{\rho g a}$ & 6.1 & $\nu=\frac{h_{0}}{L s_{0}}$ & 0.017 \\
$\delta=\frac{K_{0} L h_{0} d}{Q_{0} a}$ & $9.1 \times 10^{-3}$ & $\Omega=\frac{K_{0} L d}{Q_{0}}$ & 6.0 \\
$\varepsilon=\frac{Y c_{0}}{\rho_{B}}$ & 0.13 & & \\
\hline
\end{tabular}

Estimated values of the constants of the model are given in Table 1, and the consequent estimates of the dimensionless parameters are given in Table 2. We choose a soil permeability value typical for a common sandy silt soil. Values of the capillary suction scale $f_{0}$ may be best estimated as

$$
f_{0} \sim \sigma \sqrt{\frac{\phi}{k_{00}}}
$$

where $\sigma$ is the air-water surface tension. With our estimates, this would give $f_{0} \sim$ $0.7 \times 10^{5} \mathrm{~Pa}$, which is a reasonable value. Our tabulated estimate is consistent for values for sandy soils (Freeze and Cherry 1979).

The value of $c_{0}$ is chosen to reflect COD loading at a level of $1 \mathrm{~g}_{\mathrm{COD}} 1^{-1}$. The estimate of pipe transmissivity $T_{p}$ is based on a $10 \mathrm{~cm}$ diameter pipe with $2 \%$ perforation of the base area (for instance, three $8 \mathrm{~mm}$ diameter perforations every $7.5 \mathrm{~cm}$ ) sitting on a $30 \mathrm{~cm}$ deep gravel bed of hydraulic conductivity $10^{4} \mathrm{~m} \mathrm{~d}^{-1}$. The dispersion coefficient is based on a pore scale $d_{g}=10^{-4} \mathrm{~m}$ and a hydraulic conductivity $K_{0}$ of $10^{-5} \mathrm{~m} \mathrm{~s}^{-1} \sim 0.9 \mathrm{~m} \mathrm{~d}^{-1}$, whence $d_{g} K_{0} \sim 10^{-9} \mathrm{~m}^{2} \mathrm{~s}^{-1}$, comparable to the molecular diffusivity $D_{c}$. Thus, $D_{T} \sim D_{c}$. The values of the bioactivity coefficients $\mu_{B}, \mu_{d}, Y$, and $K_{c}$ are based on values for heterotrophs at $10{ }^{\circ} \mathrm{C}$ (Langergraber and Šimůnek 2005), while the maximal biomass density $\rho_{B}$ is an estimate (Wanner et al. 2006).

\section{Biomat Characteristics: No Ponding}

We will base our discussion around the estimates in Tables 1 and 2, but note that the values of many of the parameters depend on $K_{0}$, which is sensitive to the soil type. The principal simplification stems from the fact that, for hydraulic conductivities of the order of $K_{0} \sim 1 \mathrm{md}^{-1}$ and vadose depths of the order of $a \sim 1 \mathrm{~m}$, the time scale $\frac{a}{K_{0}} \sim 1 \mathrm{~d}$, and over time scales of interest of months or years, we may suppose the flow to be quasi-steady. This will not be the case for short term rainfall events, which are not considered here. In this quasistatic case, the downward flux $w=\Lambda q$ is steady (or time-varying on a seasonal time scale), and the saturation profile is determined by 
the solution of $(17)_{2}$,

$$
\begin{aligned}
& -\Gamma D(S) \frac{\partial S}{\partial z}=k_{r}(S)-\frac{w}{\kappa(B)}, \\
& S=1 \quad \text { on } z=0,
\end{aligned}
$$

and $w$ is determined by the boundary condition at $z=1$. Neglecting $\delta$ and $v$ in (23), we have

$$
h=\left(1-\frac{2}{3} \Omega \Theta x\right)^{1 / 2}, \quad q=\Theta\left(1-\frac{2}{3} \Omega \Theta x\right)^{1 / 2},
$$

whence

$$
w=\Lambda \Theta\left(1-\frac{2}{3} \Omega \Theta x\right)^{1 / 2} .
$$

This immediately determines the length of the pipe flow

$$
l_{F}=\frac{3}{2 \Omega \Theta},
$$

or in dimensional terms,

$$
L_{F}=\frac{3}{2 T_{p}}\left(\frac{K_{p} Q_{0}^{2} s_{0} \rho g d}{\eta_{w}}\right)^{1 / 3} .
$$

For the chosen parameter values $L_{F} \approx 2.1 \mathrm{~m}$, so that the mean flow extends over only a small fraction of the pipe length. If there is no ponding at the base of the trench, it is reasonable to associate the end of the biomat with the end of the effluent flow percolating down from the pipe, in which case the length of the biomat is $L_{B}=$ $L_{F} \propto Q_{0}^{2 / 3}$. It remains to determine $B$ and thus $\kappa$ in order to determine whether or not ponding will occur (and over what length).

On a time scale of $O\left(\gamma^{-1}\right)$, dimensionally $\sim \mu_{B}^{-1},(21)$ implies that $B$ approaches an equilibrium in which

$$
R=\lambda B, \quad \Sigma=\frac{\lambda\left(\kappa_{c}+c\right)}{c} .
$$

From $(21)_{3}$, and assuming (cf. (16)) $\Sigma=1-B$, it follows that

$$
B=1-\frac{\lambda\left(\kappa_{c}+c\right)}{c},
$$

and thus $c$ satisfies the equation

$$
\frac{\partial c}{\partial z}=\frac{\lambda \gamma}{\varepsilon w}\left[1-\frac{\lambda\left(\kappa_{c}+c\right)}{c}\right]-\frac{1}{w P e} \frac{\partial^{2} c}{\partial z^{2}},
$$

with boundary conditions

$$
c=0 \quad \text { on } z=0, \quad c=1 \quad \text { on } z=1 .
$$


From Table 2, we have, bearing in mind that $w \sim \Lambda \Theta \sim 0.43, \frac{\lambda \gamma}{\varepsilon w} \sim 7.4, \lambda \sim 0.07$, $\kappa_{c} \sim 2 \times 10^{-3}, \frac{1}{w P e} \sim 0.4 \times 10^{-3}$, and the asymptotic structure of the solution is simply obtained.

Near the top of the subsoil, $c \sim O(1) \gg \kappa_{c}$ and the dispersion term is negligible, thus

$$
c_{z}=\frac{\lambda \gamma(1-\lambda)}{\varepsilon w}
$$

so that

$$
c \approx 1-\frac{\lambda \gamma}{\varepsilon w}(1-\lambda)(1-z)
$$

and thus $c$ decreases approximately to zero over a dimensionless thickness

$$
\Delta_{B} \approx \frac{\varepsilon w}{\gamma \lambda(1-\lambda)}
$$

Since $\lambda$ is small, it follows from (35) that $B \approx 1$, pore clogging occurs, and a dense biomat is formed. In dimensional terms, its thickness is of order

$$
a_{B} \sim \frac{\varepsilon w a}{\gamma R} \sim \frac{\varepsilon \Lambda \Theta a}{\gamma \lambda}=\frac{Y c_{0} T_{p} h_{0}}{\rho_{B} \mu_{d} b} \sim 13 \mathrm{~cm},
$$

which is comparable with typical site observations of the zone of increased biological activity (McKinley and Siegrist 2010).

Below the biomat, $c \approx \frac{\lambda \kappa_{c}}{1-\lambda}$ is small, and $B \approx 0$; the basal boundary condition is then enabled through a boundary layer of thickness $\left(\frac{\varepsilon \kappa_{c}}{\gamma P e}\right)^{1 / 2} \sim 9 \times 10^{-5}$. This boundary layer is inconsequential, and we can safely ignore it by omitting the dispersion term in (36), and also the basal boundary condition for $c$.

An issue of consequence is whether the biomat which is thus formed reduces the permeability sufficiently to cause ponding to occur at the base of the gravel layer. To examine this, we examine the saturation profile given by (29). With our assumption that $\Sigma=\kappa=1-B$, then in the subsoil below the biomat we have $\Sigma=\kappa \approx 1$, and thus the solution of (29) is

$$
\int_{S}^{1} \frac{\Gamma D(S) d S}{k_{r}(S)-w} \approx z,
$$

and the saturation $S_{-}$at the base of the biomat is given by

$$
\int_{S_{-}}^{1} \frac{\Gamma D(S) d S}{k_{r}(S)-w} \approx 1-\Delta_{B} .
$$

This solution requires $w<k_{r}$ (otherwise the subsoil becomes flooded).

The formation of the biomat causes an inversion of the saturation profile, providing $w>\lambda k_{r}$. In the biomat, $\kappa=\Sigma \approx \lambda$, and thus the saturation profile in the biomat is

$$
\int_{S_{-}}^{S} \frac{\lambda \Gamma D(S) d S}{w-\lambda k_{r}(S)}=z-\left(1-\Delta_{B}\right),
$$


Fig. 2 Unponded contaminant and saturation profiles by numerical solution of (36) and (29). Parameter values are as in Table 2, with $w=0.3$ (nondimensionally)

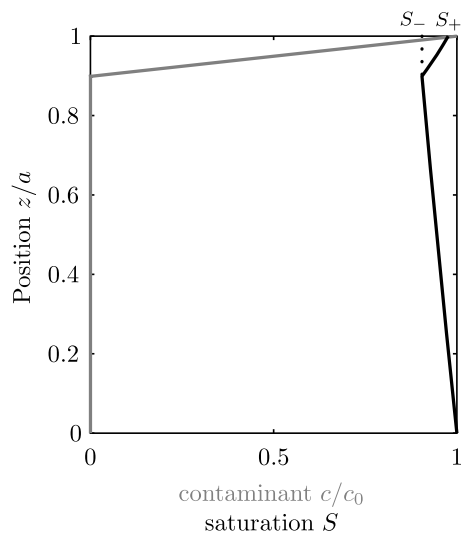

and the saturation $S_{+}$at the base of the trench is just given by

$$
\int_{S_{-}}^{S_{+}} \frac{\lambda \Gamma D(S) d S}{w-\lambda k_{r}(S)}=\Delta_{B} .
$$

We can see that $S$ decreases with depth in the biomat if $w>\lambda k_{r}$, whereas it increases in the lower subsoil if $w<k_{r}$. Figure 2 shows a typical solution of (36) and (29).

Ponding at the base of the trench is determined by the saturation profile in the biomat. We assume $w>\lambda$, otherwise ponding cannot occur. Saturation occurs if $S_{+}=1$, and thus ponding at the trench base occurs locally if

$$
\Delta_{B}=\frac{\varepsilon w}{\lambda \gamma(1-\lambda)}>\lambda \Gamma \int_{S_{-}}^{1} \frac{D(S) d S}{w-\lambda k_{r}(S)} .
$$

Equality in (46) gives a threshold value $w_{\text {crit }}$ for the downward flux which, when exceeded, marks a transition from unponded to ponded flow. The occurrence of ponded trench flow at any position along the trench invalidates the solution of the current unponded model at downstream positions. When ponding occurs, flow along the trench base can extend further downstream than the flow in the pipe, similarly extending the biomat.

If soil properties and initial biomass distribution are uniform, then infiltration is greatest at the inflow where $\left.w\right|_{x=0}=\Lambda \Theta$. Applying (46) at $x=0$ then provides a ponding criterion effectively relating the transition from unponded to ponded flow régime to the inflow rate $Q_{0}$ and the remaining parameters of the problem. Figure 3 shows the dependence of the resulting criterion on $Q_{0}$ and $K_{0}$ based on the full solution of (36) and (29) and the approximate solution (43) and (46). As explained in (6), we have for illustrative purposes taken $k_{r}(S)=S^{3}$ and $\psi(S)=1-S$. In this case, the integral in (46) can be performed analytically, resulting in an implicit algebraic expression for $w_{\text {crit }}$ to be solved iteratively. For more general soil properties, the integral must be computed numerically for each iteration but the solution approach is otherwise identical. The approximate solution agrees remarkably well with the full numerical solution, with a $3 \%$ maximum error over the parameter range in Fig. 3. 
Fig. 3 Criterion for ponding at $x=0$ in the steady state for varying $K_{0}$ and $Q_{0}$, all other parameters held constant: $(+)$ using full solution to (36) and (29); (-) using approximate solution (43), (46); (•) for the $K_{0}, Q_{0}$ values from Table 1

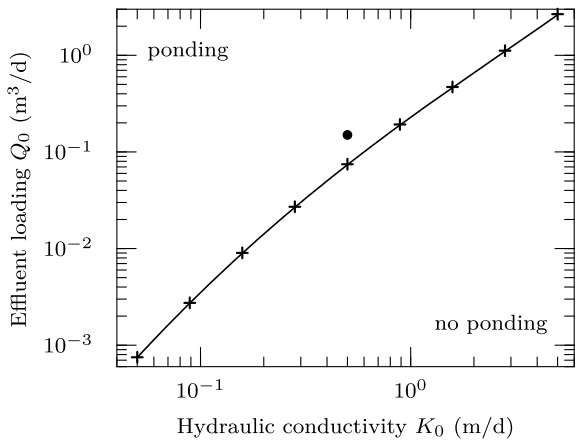

We note that with the typical parameter values of Table 2, the infiltration flux at inlet is greater than the calculated critical value. This is consistent with the expectation that flow is ponded at the trench base in normal operation. We consider the ponding situation in the next section.

\section{Biomat Characteristics: Trench Ponding}

Suppose now that ponding occurs at the base of the trench, as shown in Fig. 4. A layer of water of depth $H$ will now occur above the subsoil, and the biomat will have a saturated region of unknown thickness $a_{S}$ above the unsaturated subsoil. Equations to describe the water layer are similar to those in the pipe, and are

$$
\begin{aligned}
H_{t}+J_{x} & =\frac{q}{b}-w, \\
J & =K_{G} H\left(s_{0}-H_{x}\right), \\
w & =\frac{1}{a_{S}} K_{0} H \kappa_{B},
\end{aligned}
$$

where the drainage flux $w$ is now due to the seepage through the saturated depth of biomat due to the excess pressure head $\rho g H ; \kappa_{B}$ is the value of $\kappa$ in the biomat, and with the choices of the functions $\kappa$ and $\Sigma$ in (16), we have

$$
\kappa_{B}=\lambda \text {. }
$$

Equation (47) 1 represents the sectionally-averaged mass balance, $(47)_{2}$ specifies Dupuit type flow along the trench gravel bed, and (47) 3 gives the leakage flux percolating down through the biomat. The boundary conditions for (47) are

$$
J=0 \quad \text { at } x=0, L .
$$

Here, $K_{G}$ is the hydraulic conductivity of the gravel in the trench.

We nondimensionalize these as in (13), and in addition

$$
J \sim \frac{Q_{0}}{b}, \quad H \sim \frac{Q_{0}}{K_{G} s_{0} b}, \quad a_{S}=a \Delta_{S},
$$




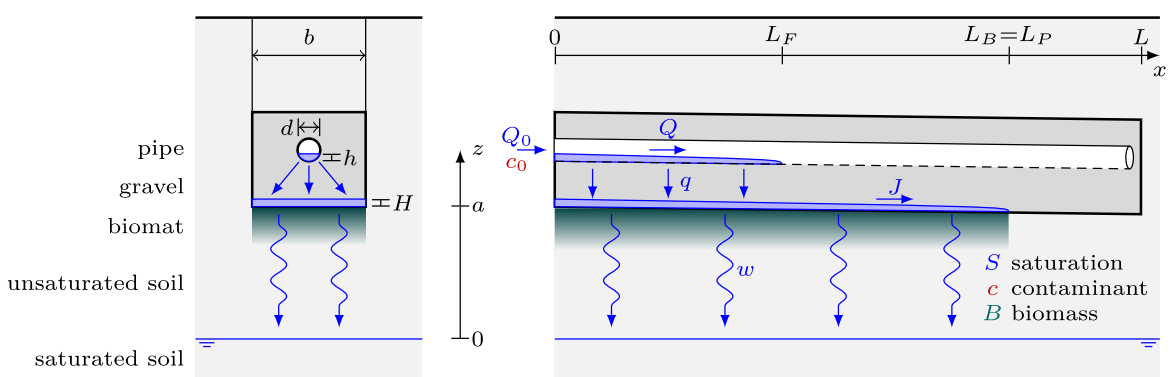

Fig. 4 Schematic transverse and longitudinal trench cross sections with ponding at the trench base

which leads to the dimensionless set

$$
\begin{aligned}
\alpha H_{t}+J_{x} & =\Omega q-\frac{\alpha H \kappa_{B}}{\Delta_{S}}, \\
J & =H\left(1-\beta H_{x}\right), \\
w & =\frac{\alpha \Lambda}{\Omega} \frac{H \kappa_{B}}{\Delta_{S}},
\end{aligned}
$$

where

$$
\alpha=\frac{K_{0} L}{K_{G} s_{0} a}, \quad \beta=\frac{Q_{0}}{K_{G} L b s_{0}^{2}} .
$$

We use the values in Table 1 , including an estimate of $K_{G} \sim 10^{4} \mathrm{md}^{-1}$ for a coarse gravel, and then

$$
\alpha \sim 0.18, \quad \beta \sim 0.07 .
$$

Neglecting the term in $\beta$, we have $J \approx H$, and in a quasisteady state, we simply have

$$
H_{x} \approx \Omega q-\frac{\alpha H \kappa_{B}}{\Delta_{S}}
$$

Suppose that $l_{F} \ll 1$, i.e., wastewater inflow is delivered near the head of the biomat. This implies (cf. (23) 1 and (27)) that $Q$ decreases from one to zero over the short length $l_{F}$, and thus that $q$ decreases rapidly to zero, with

$$
\int_{0}^{l_{F}} \Omega q d x=1 .
$$

It follows by integrating $(51)_{1}$ over the same short distance that an effective boundary condition for $J$, and hence $H$, is just

$$
H \approx 1 \text { at } x \approx 0,
$$


after which integration of (54) (with $q=0$ ) and using (48) gives the dimensionless length $l_{P}$ of the ponded trench flow as

$$
\int_{0}^{l_{P}} \frac{\Delta_{S}(x) H_{x} d x}{H}=-\alpha \lambda l_{P} .
$$

The determination of $\Delta_{S}$ follows from our earlier solution (44) for flow in the biomat, which now determines the saturated biomat thickness as

$$
\Delta_{S}=\Delta_{B}-\int_{S_{-}}^{1} \frac{\lambda \Gamma D(S) d S}{w-\lambda k_{r}(S)} .
$$

Since $\Delta_{B}=\Delta_{B}(w)$ and $S_{-}=S_{-}(w)$ are given in (40) and (43), so (58) prescribes $\Delta_{S}=\Delta_{S}(w)$. From $(51)_{3}$ and (39),

$$
w \Delta_{S}(w)=\alpha \lambda H
$$

which then defines $w$ as a function of $H$, so that (57) takes the simpler form

$$
\int_{0}^{1} \frac{\Delta_{S} d H}{H}=\alpha \lambda l_{P} .
$$

Associating the extent of biomat with the presence of vertical effluent percolation in the soil column, the biomat length is given by $l_{B}=\max \left(l_{F}, l_{P}\right)$. Figure 5 illustrates solutions for the dimensional biomat length $L_{B}$ for varying effluent flow $Q_{0}$ in a variety of cases of soil conductivity $K_{0}$, effluent concentration $c_{0}$, and microbial decay rate $\mu_{d}$. In general, for increasing flow $Q_{0}$ the biomat length follows the pipe flow length $L_{F}$ beyond the initial onset of ponding until the ponded flow extends beyond the pipe flow. For a given mean effluent flow rate $Q_{0}$, the ponded biomat length decreases with increasing soil conductivity $K_{0}$ and microbial decay rate $\mu_{d}$, and increases with increasing effluent concentration $c_{0}$ and microbial growth rate $\mu_{B}$. The sensitivity to microbial death rate appears greater than to the other parameters.

\section{Conclusions}

Drainage and remediation of wastewater outflow from septic tanks is fairly simply described as laminar open flow along the percolation pipe coupled with a vertical drainage profile described by the Richards equation. Addition of a simple description of biomass growth and consequent pore clogging yields an explicit mechanism for the formation of a biomat at the base of the trench and the possibility of ponded Dupuit type flow along the gravel bed overlying the biomat. Although it is common practice to solve such models numerically, we have shown in this paper that an essentially analytic solution can be obtained, which allows us to predict the thickness of the biomat in terms of the prescribed parameters of the model. Our theory predicts that ponding will occur at the base of the trench if the wastewater outflow from the tank is sufficiently large, and in this case the length of the biomat is increased. For systems 

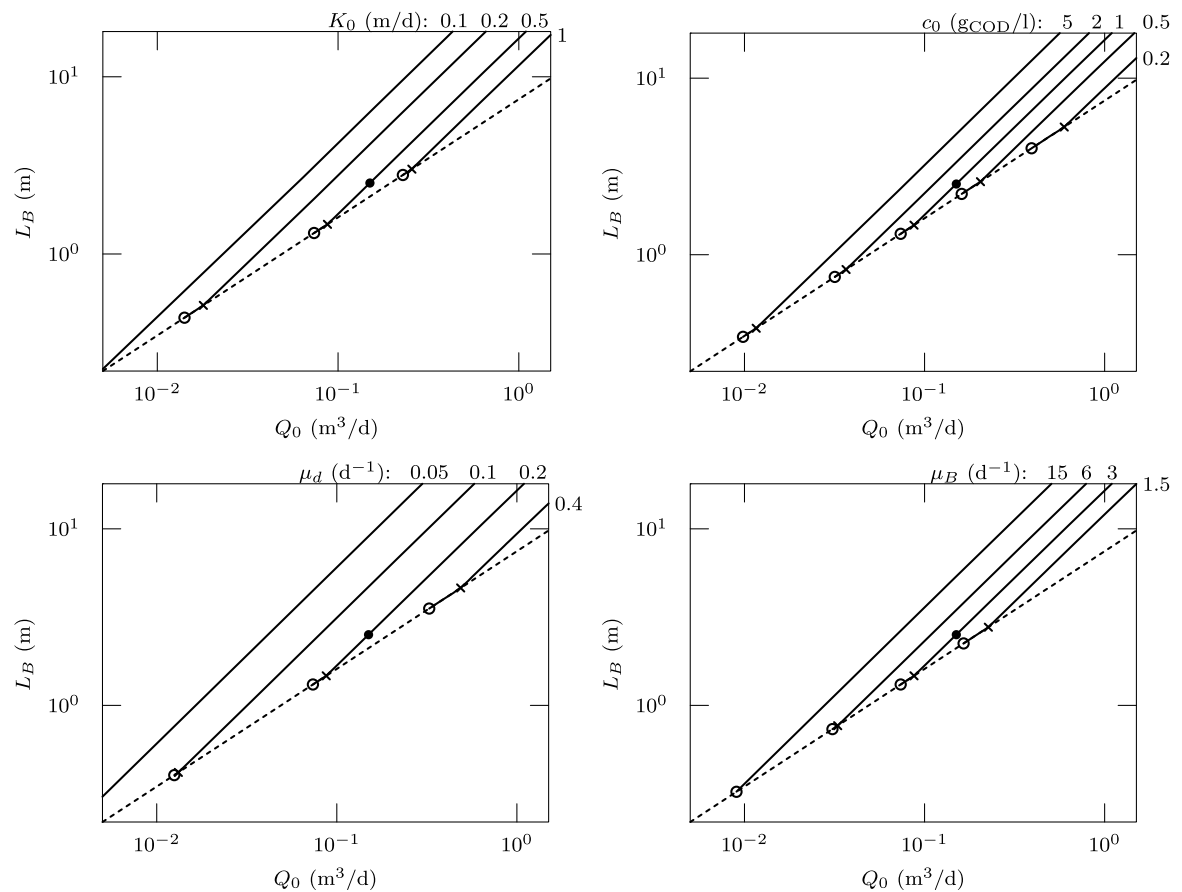

Fig. 5 Dependence of longterm biomat length on mean daily effluent flow $Q_{0}$ and (a) soil hydraulic conductivity $K_{0}$, (b) effluent contaminant concentration $c_{0}$, (c) microbial decay rate $\mu_{d}$, and (d) microbial growth rate $\mu_{B}$, with all other parameters held constant. Scales are logarithmic. The dotted line shows the pipe flow length $L_{F}$. For each conductivity value curve, (o) marks the onset of trench ponding at $x=0$, and $(\times)$ marks the extension of trench ponding beyond the pipe flow length. Points $(\bullet)$ correspond to the parameter values in Table 1

running in this ponded régime, the long term length of the biomat is dependent on effluent, soil, and microbial growth parameters in a manner predicted by the model.

The current model is based on a single contaminant component and microbial population. The inclusion of additional contaminants and metabolisms will allow for modeling of the levels of the various nonlimiting contaminants entering the underlying groundwater. Initial comparison of the current heterotroph-based model with data for nitrifiers suggests that the contribution of nitrifiers to overall biomat thickness may be an order of magnitude less than that of heterotrophs. If the contribution to permeability reduction is similarly small, then the current approximate model may be very straightforwardly extended to include the transport of multiple components. In the more general situation, the distinct contributions from the microbial populations to the flow resistance must be considered explicitly.

Further data is required to validate the model and in particular the simplifications made, but a modelling approach such as this has considerable potential to provide useful insights predicting the performance of STUs in a variety of soil and effluent conditions, and assisting in the design of STUs.

Acknowledgements This publication has emanated from research conducted with the financial support of Science Foundation Ireland under grant number 09/IN.1/I2645. 


\section{References}

Beal, C., Rassam, D., Gardner, E., Kirchhof, G., \& Menzies, N. (2008). Influence of hydraulic loading and effluent flux on surface surcharging in soil absorption systems. J. Hydrol. Eng., 13(8), 681-692. doi:10.1061/(ASCE)1084-0699(2008)13:8(681).

Finch, S., Radcliffe, D., \& West, L. (2008). Modeling trench sidewall and bottom flow in on-site wastewater systems. J. Hydrol. Eng., 13(8), 693-701. doi:10.1061/(ASCE)1084-0699(2008)13:8(693).

Freeze, R. A., \& Cherry, J. A. (1979). Groundwater. Englewood Cliffs: Prentice Hall.

Gill, L. W. (2011). The development of a code of practice for single house on-site wastewater treatment in Ireland. Water Sci. Technol., 64(3), 677-683.

Gill, L. W., O’Súlleabháin, C., Misstear, B. D. R., \& Johnston, P. J. (2007). The treatment performance of different subsoils in Ireland receiving on-site wastewater effluent. J. Environ. Qual., 36, 1843-1855. doi: $10.2134 /$ jeq2007.0064.

Gill, L. W., O’Luanaigh, N., Johnston, P. M., Misstear, B. D. R., \& O’Suilleabhain, C. (2009). Nutrient loading on subsoils from on-site wastewater effluent, comparing septic tank and secondary treatment systems. Water Res., 43(10), 2739-2749. doi:10.1016/j.watres.2009.03.024.

Huntzinger Beach, D. N., \& McCray, J. E. (2003). Numerical modeling of unsaturated flow in wastewater soil absorption systems. Ground Water Monit. Remediat., 23(2), 64-72. doi:10.1111/j.1745-6592.2003.tb00672.x.

Langergraber, G., \& Šimůnek, J. (2005). Modeling variably saturated water flow and multicomponent reactive transport in constructed wetlands. Vadose Zone J., 4(4), 924-938. doi:10.2136/vzj2004.0166.

Langergraber, G., Rousseau, D. P., García, J., \& Mena, J. (2009). CWM1: a general model to describe biokinetic processes in subsurface flow constructed wetlands. Water Sci. Technol., 59(9), 1687-1697. doi:10.2166/wst.2009.131.

Lowe, K. S., \& Siegrist, R. L. (2008). Controlled field experiment for performance evaluation of septic tank effluent treatment during soil infiltration. J. Environ. Eng., 134(2), 93-101. doi:10.1061/ (ASCE)0733-9372(2008)134:2(93).

McKinley, J. W., \& Siegrist, R. L. (2010). Accumulation of organic matter components in soil under conditions imposed by wastewater infiltration. Soil Sci. Soc. Am. J., 74(5), 1690-1700. doi:10.2136/sssaj2009.0395.

McKinley, J. W., \& Siegrist, R. L. (2011). Soil clogging genesis in soil treatment units used for onsite wastewater reclamation: a review. Crit. Rev. Environ. Sci. Technol., 41(24), 2186-2209. doi:10.1080/10643389.2010.497445.

Radcliffe, D. E., West, L. T., \& Singer, J. (2005). Gravel effect on wastewater infiltration from septic system trenches. Soil Sci. Soc. Am. J., 69(4), 1217-1224. doi:10.2136/sssaj2004.0302.

Šimůnek, J., Šejna, M., \& van Genuchten, M. Th. (2011). The HYDRUS software package for simulating the two-and three-dimensional movement of water, heat, and multiple solutes in variably-saturated media (Tech. Manual, Version 2.0). PC-Progress, Prague, Czech Republic.

Wanner, O., Eberl, H., Morgenroth, E., Noguera, D. R., Picioreanu, C., Rittmann, B. E., \& van Loosdrecht, M. C. M. (2006). Mathematical modeling of biofilms (Report of the IWA Biofilm Modeling Task Group, scientific and technical report No. 18). IWA Task Group on Biofilm Modeling, IWA Publishing, London.

Wunsch, A., McCray, J. E., Geza, M., \& Radcliffe, D. E. (2009). Modeling soil treatment units with HYDRUS-2D, constructed wetlands module (CW2D). In Proceedings of NOWRA 18th annual technical education conference \& exposition (pp. VI-Perf-AC09-32). 